\title{
RELAÇÕES MACRO/MICRO \\ NA PESQUISA EM CURRÍCULO
}

\author{
ALICE CASIMIRO LOPES \\ Faculdade de Educação da Universidade do Estado do Rio de Janeiro \\ Pesquisadora do Conselho Nacional de Desenvolvimento Cientíico e Tecnológico \\ alice@pesquisador.cnpq.br
}

\begin{abstract}
RESUMO
Este artigo analisa as relações macro/micro em teses e dissertações sobre currículo da educação básica, produzidas em programas brasileiros de pós-graduação em educação da Região Sudeste, no período de 1996 a 2002.

CURRÍCULOS - EDUCAÇÃO BÁSICA - PÓS-GRADUAÇÃO - PESQUISA EDUCACIONAL
\end{abstract}

\begin{abstract}
MACRO/MICRO RELATIONSHIPS IN THE CURRICULUM FIELD. This study analyses macro/micro relationships on PhD and master thesis on curriculum of basic education (from zero to seventeen years old) produced by the Graduate Programs in Education in Southeast Brazil, between 1996 and 2002.

CURRICULUM-BASICEDUCATION-DOCTORAL PROGRAMMES - EDUCATIONAL RESEARCH
\end{abstract}

Este artigo foi elaborado com base em apresentação realizada na mesa-redonda Produção do conhecimento, pós-graduação e pesquisa na Região Sudeste: reflexões epistemológicas, do $6^{\circ}$ Encontro de Pesquisa em Educação da Região Sudeste, realizado de 12 a 15 de junho de 2005. 
Ah, que ânsia humana de ser rio ou cais! Barrow-on-Furness, Álvaro de Campos

Este artigo visa contribuir para a compreensão da pesquisa em educação, por considerar ser esse um tema sempre fundamental e que exige diferentes focos e interpretações, não apenas visando à análise crítica do que é realizado, mas à produção de sínteses que contribuam para o desenvolvimento do campo. Na linha do que outros trabalhos já realizaram (Alves-Mazzotti, 200 I; André, 200 I; Gatti, 200 I), busco compreender limites e possibilidades dos enfoques teórico-metodológicos assumidos. Diferencio-me, entretanto, por pensar o campo da educação com base em um de seus subcampos: o de currículo'.

Nessa análise, eminentemente epistemológica, assumo a compreensão bachelardiana de epistemologia (Bachelard, 1984, 1985, 1986), a qual se contrapõe às perspectivas epistemológicas normativas, que se julgam na obrigação de estabelecer a priori os princípios de como produzir o conhecimento científico. Com base na perspectiva de Bachelard, sempre busquei (Lopes, 1999) salientar o caráter histórico da produção do conhecimento, seu compromisso com racionalismos setoriais dependentes dos contextos das práticas científicas e garantidores dos acordos provisórios que definem a veracidade dos discursos das múltiplas ciências. Dessa forma, o objeto de pesquisa nunca está dado, mas é construído na relação com a teoria, a linguagem, o sujeito cognoscente, a empiria e as práticas de investigação.

Na perspectiva bachelardiana, são profundamente questionadas a razão cartesiana e as concepções monistas de verdade e conhecimento. A verdade passa a ser concebida nos termos de uma veracidade sobre a qual se deve argumentar empírica e discursivamente, sendo, portanto, provisória, condicionada e razoável. O conhecimento, por sua vez, se modifica em razão das disputas argumentativas em torno do que se compreende historicamente como verdade.

Para além da perspectiva bachelardiana, saliento o caráter de construção social do conhecimento. Tal caráter remete toda discussão epistemológica à análise das opções políticas e sociais por certos modos de produzir conhecimento, aos embates e conflitos associados a esse processo e às relações de

I. Para o entendimento da concepção de campo do currículo, ver Lopes e Macedo (2002) e Macedo et al. (2004). 
poder que, em dado momento histórico, legitimam certas formas de conhecer em detrimento de outras. A análise epistemológica, portanto, não é realizada do "alto", de um lugar "fora da pesquisa", "fora da ação cotidiana de pesquisar". Por exemplo, focalizo neste artigo uma questão epistemológica que perpassa minhas pesquisas sobre currículo, mas que se insere, igualmente, nos atuais debates educacionais e das ciências sociais de uma forma mais ampla (Brandão, 200 I , 2002). Refiro-me à dualidade da investigação sobre macroestruturas político-sociais e econômicas e sobre microcontingências, envolvendo sujeitos, ações e instituições, aqui denominadas relações macro/micro.

Entendo ser possível evidenciar alguns modos de como tais relações têm sido abordadas na educação, bem como construir um debate que favoreça a superação da dicotomia ainda presente na forma de algumas pesquisas entenderem a relação macro/micro. Esse debate assume maior relevância quando associado às discussões centrais sobre a nossa assim chamada condição pósmoderna: as relações entre estrutura e ação, totalidade e fragmento, transcendência e contingência. Os discursos estruturais, marcados pelo caráter transcendente, que busca de diferentes formas a constituição de totalidades orgânicas e unificadas, são característicos da modernidade, fazendo com que os discursos pós-modernos a eles se contraponham, por considerá-los opressores da contingência, da diferença, do local e do específico. Com essa associação, não afirmo que toda pesquisa de instâncias micro, envolvendo contingências, sujeitos, ações e instituições, assume perspectivas teóricas pós-estruturais e/ou pós-modernas, mas a disseminação de concepções pós-estruturais valoriza os discursos das microinstâncias, freqüentemente desconsiderados por matrizes estruturais e modernas. Assim, penso que compreender como as pesquisas macro e micro têm-se desenvolvido no campo educacional contribui para o posicionamento diante desse atual debate nas ciências sociais.

No que concerne às pesquisas realizadas na Região Sudeste, minha reflexão tem por referência o estado da arte sobre a produção relativa a currículo da educação básica nas teses e dissertações de 1996 a 2002 (Macedo et al., 2004), realizado com apoio do Instituto Nacional de Pesquisas Educacionais Inep/ Programa das Nações Unidas para o Desenvolvimento - PNUD - e da Associação Nacional de Pós-Graduação e Pesquisa em Educação - Anped. Saliento, contudo, que não focalizo o campo do currículo como exemplar ou ainda como reflexo das discussões mais gerais no campo educacional. Apenas consi- 
dero, no que tange ao foco de investigação escolhido, que os debates no campo do currículo se articulam com os debates mais amplos do campo educacional, de forma que este campo pode se beneficiar do entendimento de questões curriculares.

\section{AS PRODUÇÕES INVESTIGADAS: INSTÂNCIAS MACRO E MICRO}

$\mathrm{Na}$ investigação em pauta, foram privilegiadas as produções fundamentadas em grupos e linhas de pesquisa em currículo e que, dessa forma, são entendidas como capazes de constituir o campo do currículo, não incluindo produções isoladas em programas sem pesquisa específica na área. Foram levantadas, portanto, as produções de programas com linhas de pesquisa e/ou eixos temáticos em currículo, projetos de pesquisa institucionais vinculados ao campo do currículo e/ou com pesquisadores em seus quadros docentes que publicam na área e participam de fóruns específicos sobre a temática. Pela restrição do escopo da pesquisa ao currículo da educação básica, não foram incluídos trabalhos sobre formação de professores, ensino superior e ensino técnico, bem como sobre currículo e estudos culturais quando o trabalho empírico se desenvolveu fora da escola (Macedo et al., 2004). Tomando um recorte do levantamento realizado nessa pesquisa, focalizo neste trabalho a Região Sudeste, totalizando 269 teses e dissertações (ver Tab. I) produzidas entre 1996 e 2002 e distribuídas em 13 programas credenciados, a saber, Pontifícias Universidades Católicas: PUC/Minas Gerais, PUC/São Paulo (Programas de História da Educação e de Supervisão e Currículo), PUC/Rio de Janeiro; universidade estaduais: do Rio de Janeiro - Uerj -, Paulista - Unesp/ Araraquara -, de Campinas - Unicamp -, de São Paulo - USP; universidades federais: do Espírito Santo - Ufes -, Fluminense - UFF -, de Minas Gerais UFMG -, do Rio de Janeiro - UFRJ. Essas teses e dissertações compreendem 59\% do total de produções em currículo investigadas na pesquisa (Macedo et al., 2004). Com base nesses textos completos ${ }^{2}$ foram elaborados resumos e organizado o banco de dados do material.

2. Aproveito para agradecer publicamente a colaboração dos programas de pós-graduação e das bibliotecas das respectivas universidades na obtenção do material. Sem essa colaboração o trabalho não se realizaria a contento. 
TABELA I

NÚMERO DE TESES E DISSERTAÇÕES RESUMIDAS POR INSTITUIICÃ̃ (I996/2002)

\begin{tabular}{l|c|c}
\hline PROGRAMA & Teses & Dissertações \\
\hline PUC/SP Supervisão e Currículo & 15 & 29 \\
PUC/SP História da Educação & 1 & 16 \\
PUC-MG & 0 & 7 \\
UERJ & 0 & 14 \\
UFRJ & 3 & 10 \\
UNESP/AR & 1 & 5 \\
USP & 23 & 25 \\
PUC-Rio & 1 & 5 \\
UNICAMP & 17 & 28 \\
UNIMEP & 0 & 30 \\
UFES & 0 & 4 \\
UFF & 2 & 10 \\
UFMG & 4 & 14 \\
\hline Total & 67 & 202 \\
\hline
\end{tabular}

Para além da análise específica das relações macro/micro, destaco que os estudos são predominantemente associados a perspectivas sociológicas e filosóficas de enfoque crítico, confirmando o que já foi evidenciado no quadro nacional (Macedo et al., 2004). Na Região Sudeste, são ausentes os estudos de caráter instrumental (administrativo-científico), bem como pouco freqüentes são os estudos da diferença, as genealogias e arqueologias, em enfoques pós-estruturalistas (apenas oito estudos em 269, o que correspondente a 3\% do total). No que concerne aos enfoques pós-estruturalistas, esse resultado é decorrente do que já havia sido identificado no quadro nacional (Macedo et al., 2004): nas teses e dissertações, tais estudos estão concentrados no programa da Universidade Federal do Rio Grande do Sul - UFRGS.

Igualmente, é importante destacar a alta produtividade do campo, com a investigação de objetos bem diversificados, ainda que marcadamente vinculados à prática curricular, seja do currículo escolar como um todo ou de um componente curricular específico. Tal produtividade é coerente com o significativo avanço do campo da educação nos últimos 20 anos: houve a ampliação dos programas de pós-graduação, dos grupos de pesquisa e das linhas de fi- 
nanciamento, bem como a diversificação, a meu ver, altamente frutífera de temas, teorias e métodos de investigação.

De certa forma, os problemas teórico-metodológicos com os quais nos envolvemos hoje são também coerentes com esse avanço. Na medida em que tornamos mais complexos nossos objetos de pesquisa e que aprofundamos nossas interpretações teóricas, nos envolvemos em novos desafios e surgem questões que anteriormente não estavam em pauta. Se por um lado estamos imersos em um cotidiano marcado pela performatividade e pelo constante processo de nos inventar a nós mesmos como pesquisadores e produtores de conhecimento (Ball, 2004; Lyotard, 1986), mais ou menos cientes dos perigos de afastamento de uma autenticidade epistemológica, por outro, ambiguamente, construímos o amadurecimento do campo de pesquisa educacional e assumimos novos riscos decorrentes de nossas escolhas nesse processo.

Um dos riscos, a meu ver, está associado a como são analisadas as relações entre as instâncias macro e micro, ora dicotomizando-as e pensando uma autonomia de uma dessas instâncias diante da outra, ora estabelecendo relações causais imediatas entre elas (Brandão, 2001 , 2002). Saliento que minhas pesquisas incluem-se nesses riscos, pois considero que nem sempre escapo/ escapei de tais problemas epistemológicos.

Para o desenvolvimento da pesquisa dessas relações, optei por classificar as teses e dissertações da Região Sudeste em abordagens macro e micro com base no trabalho empírico realizado. A escolha do foco no trabalho empírico, em detrimento da análise do corpo teórico-metodológico como um todo, foi decorrente de ser mais precisa sua definição nas teses e dissertações. Com isso, se estabelece um primeiro limite desta pesquisa, pois o foco do trabalho empírico nem sempre é diretamente associado ao que podemos denominar instâncias macro e micro nas pesquisas históricas e políticas. Por exemplo, pode vir associado às discussões psicológicas e/ou antropológicas, assumindo contornos epistemológicos diversos dessa distinção. Ainda assim, considero que a abordagem das fontes do trabalho empírico nas investigações sobre currículo é indicativa de algumas distinções teórico-metodológicas desenvolvidas, capazes de se associar ao micro e ao macro.

Situei como trabalhos associados à instância macro as pesquisas que focalizaram: as disposições legislativas; as propostas curriculares oficiais, incluindo a história dessas disposições e propostas; a história das disciplinas no siste- 
ma educacional, seja por intermédio de documentos oficiais e/ou livros didáticos; a análise da organização curricular ou da seleção de conteúdos do currículo ou de um componente curricular específico no sistema educacional. Como trabalhos que focalizaram as instâncias micro, situei dissertações e teses que utilizaram uma metodologia centrada na investigação: do cotidiano da escola ou da prática pedagógica; das concepções dos sujeitos em uma dada instituição escolar ou da instituição escolar como um todo; do uso dos livros didáticos, incluindo a história do currículo com privilégio da investigação do cotidiano escolar; os estudos de caso de forma geral. Para os propósitos desta investigação, não diferenciei as instâncias micro das instâncias meso (institucionais), tal como definidas por Nóvoa (1995). Os estudos teóricos, bem como os que focalizaram trabalhos empíricos com o pensamento curricular, sem relacionar esse pensamento com as dimensões anteriormente definidas como macro ou micro, não foram classificados em uma ou outra dimensão (ver Tabs. 2 e 3). Estes representam um total de 29 teses e dissertações, reduzindo para 240 o número de trabalhos que focaliza as relações macro e/ou micro.

TABELA 2

DISSERTAÇÕES E TESES SEGUNDO PRESENÇA OU AUSÊNCIA DE ABORDAGEM MACRO/MICRO

\begin{tabular}{l|c|c|c|c|c}
\hline Classificação & Macro & Micro & Macro/micro & Sem classificação & Total \\
\hline Número de teses e dissertações & 67 & 116 & 57 & 29 & 269 \\
Percentuais & 24,9 & 43,1 & 21,2 & 10,8 & 100 \\
\hline
\end{tabular}

TABELA 3

DISSERTAÇÕES E TESES SEGUNDO ABORDAGEM MACRO/MICRO

\begin{tabular}{l|c|c|c|c}
\hline Classificação & Macro & Micro & Macro/micro & Total \\
\hline Número de teses e dissertações & 67 & 116 & 57 & 240 \\
Percentuais & 27,9 & 48,3 & 23,8 & 100 \\
\hline
\end{tabular}

É possível observar que dos 240 estudos, quase a metade (48,3\%) privilegia os estudos micro. Os estudos macro vêm em segundo lugar (67, equivalendo a $27,9 \%$ ), seguidos de perto pelos estudos que articulam macro e micro (57, correspondendo a 23,8\%). Tal diferença é coerente com a especificidade do campo do currículo, cujo objeto é entendido como uma produção da esco- 
la, bem como contradiz a idéia de que são poucos os estudos curriculares sobre a escola. Ao contrário, as teses e dissertações evidenciam que a escola é o lócus central de investigação, associado à preocupação com a inovação curricular e o entendimento das relações sociais que se desenvolvem na ação curricular.

Tal ênfase na escola por vezes expressa uma separação entre o chamado currículo formal - freqüentemente, mas não exclusivamente, assinado por instâncias oficiais - e o currículo em ação, desenvolvido na escola. Não se trata de questionar a validade de estudos que se concentram no sistema educacional ou na escola, pois tais estudos podem ser realizados sem que obrigatoriamente impliquem uma dicotomia entre currículo em ação e currículo formal, mas, ao contrário, se constituam pesquisas de dimensões diversas de um mesmo objeto: o currículo. É significativa, contudo, a existência de tão poucos estudos que enfrentem as dificuldades de articular, em uma mesma pesquisa, as duas dimensões.

Pela análise da predominância desses enfoques com o passar dos anos investigados (Tab. 4), não se constata alteração expressiva desse quadro. Apenas se encontra um ligeiro declínio dos estudos micro com a conseqüente ampliação dos estudos macro/micro, talvez decorrente da produção de propostas curriculares em nível nacional ao longo dos anos 1990, tendo levado os pesquisadores a se interessarem particularmente por investigar seu impacto sobre a prática.

TABELA 4

PREDOMINÂNCIA DOS ESTUDOS MACRO E MICRO EM RELAÇÃO AOS ANOS

\begin{tabular}{l|r|r|r|r|r|r|r|r}
\hline Ano & & 1996 & 1997 & 1998 & 1999 & 2000 & 2001 & 2002 \\
\hline Estudos macro & $\mathrm{N} \%$ & $7(0,27)$ & $7(0,30)$ & $5(0,21)$ & $8(0,31)$ & $14(0,35)$ & $12(0,24)$ & $14(0,30)$ \\
Estudos micro & $\mathrm{N} \%$ & $15(0,58)$ & $12(0,52)$ & $16(0,67)$ & $8(03 \mid)$ & $19(0,41)$ & $25(0,51)$ & $21(0,46)$ \\
Estudos macro/micro & $\mathrm{N} \%$ & $4(0,15)$ & $4(0,17)$ & $3(0,13)$ & $10(0,38)$ & $13(0,28)$ & $12(0,24)$ & $1 \mathrm{II}(0,24)$ \\
\hline Total por ano & $\mathrm{N}$ & 26 & 23 & 24 & 26 & 46 & 49 & 46 \\
\hline
\end{tabular}

Nos estudos macro, predominam as pesquisas sobre propostas curriculares oficiais, como os parâmetros curriculares nacionais e seus temas transversais, seja abordando o conjunto de documentos ou documentos disciplinares específicos, e os diversos sistemas legislativos, atuais ou analisados historicamente, seguidos da análise de livros didáticos. Trata-se de investigações com contribuições importantes para o campo, ainda que, algumas vezes, 
expressem uma relação determinista para com a prática pedagógica, como se os textos, sejam eles livros, dispositivos legais ou parâmetros, não fossem reinterpretados e reinventados na prática. Muitas vezes, as leituras desses textos, ao invés de serem apresentadas como possíveis leituras a serem realizadas, assumem o discurso de leitura unívoca, cabendo à prática pedagógica sua aceitação. Tal concepção pode ser identificada tanto em trabalhos que defendem as proposições desses documentos quanto em trabalhos que criticam os documentos investigados. Para os primeiros, cabe à escola seguir tais orientações de forma a garantir a qualidade da educação; para os segundos, mesmo existindo a crítica, as escolas estão fadadas a se submeterem às conseqüências das definições textuais, pois estão inseridas em um marco estrutural do qual dificilmente se escapa.

Na mesma linha de uma interpretação unívoca dos textos, é perceptível a reduzida presença de estudos que investigam a elaboração dos documentos, apresentando os conflitos entre grupos de autores e/ou a produção das ambivalências de sentidos nos textos. Com isso, é reforçada uma concepção prescritiva sobre a prática, como se os textos fossem fechados a múltiplas leituras e não marcados pela polissemia, ainda que limitada por relações de poder e pelo contexto histórico de leitura (Ball, 1994).

caráter prescritivo também pode ser constatado na abordagem da seleção de conteúdos. É freqüente a elaboração de pesquisas que buscam argumentar e/ou apresentar evidências em defesa da inclusão de um conteúdo de ensino, seja por critérios epistemológicos, psicológicos ou de relevância social, situados a partir de um referencial fora das relações conflituosas que definem os conteúdos de um currículo. Pelo não-diálogo com instâncias micro e por desconsiderarem o caráter produtivo dessas instâncias, por vezes os estudos macro mascaram a contingência. Com isso, as instâncias micro são interpretadas como homogêneas, ou porque essa homogeneidade é considerada a priori, ou porque a heterogeneidade é suposta como possível de ser reduzida a elementos simples e fundamentais. Processos complexos e matizados a história das disciplinas, as políticas de currículos, a produção do conhecimento escolar, a produção de livros didáticos, as concepções de professores, a seleção e a organização de conteúdos - tendem a ser simplificados por mecanismos de apagamento de suas diferenças e não por inclusão dessas diferenças em um sistema amplo de interpretação. 
No caso de estudos micro, por sua vez, é possível, ainda, perceber o isolamento do contingente sem a preocupação de construir elementos que associem o específico com o geral. Ainda são freqüentes estudos que focalizam a escola ou a sala de aula como uma unidade isolada, sendo o currículo desenvolvido uma decorrência quase exclusiva das concepções dos sujeitos atuantes na prática. Se por um lado tais estudos contribuem para valorizar a ação dos sujeitos, não os interpretando como determinados mecanicamente por estruturas sociais, por outro, podem contribuir para idealizar essa ação. Considero que o campo tem avançado sobremaneira no entendimento dos fluxos do cotidiano, suas permanências e singularidades, e das dimensões subjetivas que entram em jogo quando esses fluxos são construídos (Alves, Oliveira, 2002). Foi aprofundada a compreensão do caráter produtivo da escola, das especificidades institucionais que fazem com que o currículo se constitua em não-unitário, mas ainda assim considero importante ampliar nossos estudos a fim de produzir nexos entre a diversidade da prática pedagógica e relações mais gerais.

Quando tais nexos não são desenvolvidos, é possível constituir um determinismo às avessas: a microanálise gerando conclusões macro sem mediações. Tal característica é particularmente presente em trabalhos que investigam concepções de professores, sem analisar como as especificidades dessas concepções são engendradas no contexto institucional ou mediadas por questões locais específicas. Com isso, as concepções identificadas em um pequeno número de professores são associadas ao universo do professorado de forma imediata e utilizadas para justificar problemas no desenvolvimento dos currículos.

Outra decorrência da falta de nexos entre macro e micro é a investigação do currículo na escola com uma concepção prévia de como esse currículo deveria ser. A partir de um dado modelo de currículo, muitas vezes baseado em princípios da teoria crítica, a prática pedagógica é analisada, considerando sua maior ou menor aproximação do modelo idealizado. Com isso, mais uma vez é assumida uma perspectiva prescritiva sobre a prática, não sendo realizada a investigação, orientada pela teoria crítica ${ }^{3}$, de por que a escola é como é e de como são constituídas, nas condições concretas de trabalho da escola, as soluções curriculares existentes.

3. Para uma análise mais detalhada da contradição entre base teórica crítica e tendência prescritiva, ver Macedo et al. (2004). 
Outra ausência significativa nas teses e dissertações em instâncias micro são os estudos sobre alunos e sua experiência em sala de aula, com exceção para as investigações sobre concepções alternativas no ensino de ciências, que, por sua vez, se limitam ao enfoque cognitivo, sem analisar dimensões culturais mais amplas. Goodson e Anstead (1998) defendem que as práticas institucionais e as relações e estruturas sociais são mutuamente constitutivas. Assim, propõem que no estudo de caso de uma escola sejam consideradas tanto as relações entre estruturas e práticas institucionalizadas escolares, quanto o papel das várias pessoas implicadas nessas práticas, incluindo-se os alunos, entendidos como sujeitos que também produzem o currículo.

Nas pesquisas que focalizam as relações macro/micro (57 em 240, eqüivalente a $23,8 \%$ ), são predominantes os objetivos de investigar como propostas oficiais (federais, estaduais e municipais) são implementadas nas esco$\operatorname{las}^{4}$. Dentre essas, predomina o enfoque prescritivo, apesar de o enfoque teórico assumido ser quase sempre associado à teoria crítica de currículo, como já mencionado. O foco da análise, de forma geral, é a identificação dos limites e das possibilidades para a implementação da proposta curricular na escola. Freqüentemente conclui-se haver necessidade de mudanças na formação de professores e melhoria das condições de trabalho docente, de maneira a garantir a "correta" aplicação prática dos princípios da proposta. Dessa forma, mesmo havendo um discurso crítico em relação às ações políticas de governo, por serem incapazes de garantir as condições necessárias à reforma educacional pretendida, as conclusões tendem a responsabilizar os professores pelo que é entendido como falta de inovação curricular. Essa tendência é ainda mais comum quando o pesquisador se identifica com os princípios curriculares da proposta em pauta, chegando mesmo a utilizá-los como pressuposto teórico de sua investigação.

Ainda assim, há significativos estudos que apontam para uma perspectiva mais dinâmica da relação macro/micro, especialmente quando investigam: a participação de professores nas propostas, os conflitos na produção das propostas, a participação dos movimentos sociais na constituição da mudança cur-

4. Para uma análise crítica dessa concepção de que as propostas curriculares oficiais são apenas implementadas (ou não) na prática curricular, com base no modelo de Stephen Ball, ver Lopes (2004a). 
ricular, a história das práticas institucionais, bem como a articulação do pensamento curricular com a produção de propostas curriculares, assinadas ou não pela esfera oficial. Nesses casos, em virtude tanto da ampliação e diversificação de fontes quanto de um objeto que privilegia conflitos e tensões nos processos, a construção teórico-metodológica tende a ser desenvolvida de forma a evitar dicotomias macro/micro.

Há notoriamente dificuldades de construção teórico-metodológica capaz de dar conta das especificidades de investigação no macro e no micro, problema que não se restringe ao campo do currículo (Brandão, 200 I , 2002). Usualmente, nas teses e dissertações da região Sudeste, seguindo a tendência do quadro nacional (Macedo et al., 2004), a discussão metodológica se restringe à afirmação das técnicas a serem utilizadas. Com isso, é desconsiderado o entendimento da metodologia como profundamente correlacionada à construção teórica: o caminho de pesquisa é limitado à escolha das técnicas de forma empirista e não tido como uma decorrência das opções téorico-metodológicas realizadas (Cardoso, s.d.). Nessa perspectiva, a etnografia é privilegiada nas investigações nas escolas, seguida das entrevistas e questionários, e a análise de documentos é privilegiada nas instâncias macro, muitas vezes desconsiderando-se o processo de elaboração e os sujeitos produtores dos documentos, bem como a circulação de múltiplos textos e discursos nessas instâncias. Entendo que o avanço nessa construção teórico-metodológica pode ser facilitado pela interpretação não-dicotômica das relações entre fragmento e totalidade, entre contingência e transcendência, entre macro e micro.

\section{PARA UMA CONSTITUIÇÃO TEÓRICO-METODOLÓGICA DAS RELAÇÕES MACRO/MICRO}

Não estou questionando a hipótese de a pesquisa privilegiar empiricamente instâncias macro ou instâncias micro, mas aponto o problema da análise de cada uma dessas instâncias que não considera as relações com a outra ou apenas considera relações deterministas entre elas. Como decorrência, questiono também o que entendo como conseqüências dessa análise dicotômica: a perspectiva prescritiva sobre a prática pedagógica nas escolas que deriva, muitas vezes, de não se levar em conta as dinâmicas produtivas do cotidiano escolar, e a perspectiva realista de análise das práticas pedagógicas, 
resultante, em muitas situações, de uma centralidade exclusiva nas dinâmicas microeducacionais ou de um determinismo nas relações macro/micro.

Muito provavelmente, os problemas aqui expostos são superados, na medida em que as conclusões das dissertações e teses são articuladas em um projeto maior dos grupos de pesquisa aos quais estão associadas. Ou seja, mesmo teses e dissertações que, isoladamente, não desenvolvem a articulação macro/micro contribuem com discussões teóricas e evidências empíricas que, em conjunto, permitem a leitura dessas articulações e o entendimento da complexidade heterogênea do todo social. Tal fato é plenamente justificável, pois especialmente as dissertações de mestrado, trabalhos realizados em prazos exíguos, têm dificuldades para dar conta de questões mais complexas, que exigem a articulação de múltiplas fontes e questões teóricas. Considerando o tempo e as condições em que são realizados, há que se valorizar, sobretudo, o que é alcançado. Ainda assim, é pertinente o debate sobre os problemas epistemológicos decorrentes dessa dicotomia das instâncias macro e micro, de forma a mantermos uma vigilância epistemológica constante, nos termos bachelardianos, contra o realismo, o determinismo e as dicotomias. Afinal, tais problemas epistemológicos atravessam a história da investigação em ciências sociais, não sendo superados de uma vez por todas.

Significativamente, os riscos do realismo existem tanto na abordagem das microinstâncias quanto da abordagem da estrutura social. $\bigcirc$ foco na totalidade pode se converter em apagamento das diferenças, de ser o "auto-de-fé estrutural" que visa a estabelecer princípios e metas para prescrever a realidade. No campo do currículo, isso se evidencia quando a teoria crítica é instrumento de construção dos princípios sobre como a escola deve ser, como a formação de professores deve ser, sem que se entenda porque são do jeito que são e como se constituem no cotidiano das relações sociais concretas, capazes de mediar pedagogicamente as estruturas sociais e econômicas.

Por sua vez, a valorização do singular e do contingente pode se converter em uma perspectiva nominalista, em que cada coisa é cada coisa, cara ao realismo no estilo de Alberto Caeiro: "A Realidade é apenas real e não pensada" ${ }^{5}$. Nesse caso, a linguagem deixa de ser entendida como mediadora, por-

5. Do poema O único mistério do universo. 
que constitutiva do real, tornando-se mero veículo da descrição e, por vezes, da celebração dessa realidade diversa.

De forma a superarmos esse dualismo que impõe limites realistas e deterministas às investigações, penso ser importante considerar que há um cotidiano constitutivo das macroestruturas, assim como há relações sociais gerais que unem contingências locais, constituindo o que Brandão (200I) denomina potencial interativo micro e macro. Penso que McLaren (1997, 1997a; McLaren, Giroux, 1997) pode ajudar no entendimento desse processo ao recuperar em novas bases a concepção de totalidade de Marx.

Na perspectiva marxista, a concepção de realidade empirista é superada pela defesa da realidade social como um todo estruturado em suas múltiplas determinações, contraditório e possuidor de uma ordem que não está dada, não é aparente, além de ser histórica e ideológica (Kosik, 1986). A totalidade é sempre mais do que a soma das partes, pois inclui as contradições entre as partes e seus processos de mediação. Trata-se de uma totalidade aberta, que engloba múltiplas totalidades (Lefèbvre, 1955) e que não pode ser compreendida pela via sensorial, mas pelo entendimento de como os fragmentos do real adquirem sentido na totalidade.

McLaren reconfigura essa interpretação, pelo questionamento às totalidades opressoras e reducionistas, capazes de violentar a especificidade dos eventos, em nome da idéia do que há de comum, sem questionar quem tem o poder de significar e definir a construção do que é entendido como comum. Tais totalidades são capazes de apagar as especificidades dos eventos quando nela incluídos, levando à construção de metanarrativas universais (Lyotard, 1986), discursos que não se submetem aos próprios princípios de julgamento que impõem aos demais discursos.

No entanto, McLaren também considera importante questionar a ditadura do fragmento, na qual é valorizada a pluralidade de diferenças e de eventos, sem conexões e relações. Principalmente porque, com base em Jameson, ele não vê possibilidades de uma atuação política sem que se opere simultaneamente nos níveis micro e macro, articulando lutas locais e globais.

A opção por esses dois caminhos epistemológicos não é, por sua vez, um meio termo ou uma passagem apressada dos fragmentos à totalidade, ou desta aos fragmentos, com a construção de relações causais capazes de apagar a complexidade das mediações. McLaren defende a associação do concei- 
to de totalidade à valorização do contingente, do local e da diferença, ressignificando-o. Citando Teresa Ebert (McLaren, 1997), ele compreende a totalidade como um sistema de relações e uma estrutura da diferença sobredeterminados, heterogêneo e historicamente específico. Dessa forma, é preciso interpretar as relações entre as diferenças sem congelá-las em um modelo único e fixo. Não se trata de produzir uma generalização da multiplicidade de efeitos locais para produzir um fenômeno global, mas de entender as conexões mutuamente constitutivas entre o global e o local, entre o específico e o geral.

Como já mencionei, não considero que as dificuldades de uma construção teórico-metodológica como essa sejam particularidade do campo educacional; nas ciências sociais, de forma geral, enfrentamos hoje esse desafio. Para além do debate moderno/pós-moderno, estruturalismo/pós-estruturalismo, entendo ser necessário que superemos as dificuldades de articulação entre instâncias macro e micro. Dessa forma, penso ser possível contribuir não apenas para a constante ampliação da fertilidade de nossas pesquisas, mas para a politização do conhecimento e para a ampliação de nossa capacidade de articular lutas sociais emancipatórias coletivas que não silenciem as diferenças.

\section{REFERÊNCIAS BIBLIOGRÁFICAS}

ALVES, N.; OLIVEIRA, I. B. Uma história da contribuição dos estudos do cotidiano escolar ao campo do currículo. In: LOPES, A. C.; MACEDO, E. (org.) Currículo: debates contemporâneos. São Paulo: Cortez, 2002. p.78-102.

ALVES-MAZZOTTI, A. J. Relevância e aplicabilidade da pesquisa em educação. Cadernos de Pesquisa, São Paulo, n.I I3, p.39-50, jul. 2001.

ANDRÉ, M. Pesquisa em educação: buscando rigor e qualidade. Cadernos de Pesquisa, São Paulo, n. I I3, p. 5I-64, jul. 200 I.

BACHELARD, G. A Filosofia do não. Lisboa: Presença, 1984.

O Novo espírito científico. Rio de Janeiro: Tempo Brasileiro, 1985. Le Rationalisme appliqué. Paris: Presses Universitaires de France, 1986.

BALL, S. J. Education reform: a critical and post-structural approach. Buckinghan: Open University, 1994. 
Performativities and fabrications in the education economy. In: BALL, S. J. (org.) The Routledge Falmer reader in sociology of education. London, New York: Routledge Falmer, 2004. p. $14 \mid-155$.

BRANDÃO, Z. A Dialética micro/macro na sociologia da educação. Cadernos de Pesquisa, São Paulo, n. I I3, p. 153-165, jul. 200 I .

Pesquisa em educação: conversas com pós-graduandos. Rio de Janeiro: PUC-Rio, Loyola, 2002. p. 95- I05: Para além das ortodoxias: a dialética micro/macro na sociologia da educação, p.95- 105.

CARDOSO, M. L. O Mito do método. Boletim Carioca de Geografia, Rio de Janeiro, v.25, p.6I-100, s.d.

GATTI, B. Implicações e perspectivas da pesquisa educacional no Brasil contemporâneo. Cadernos de Pesquisa, São Paulo, n. I 13, p.65-81, jul. 2001 .

GOODSON, I.; ANSTEAD, C. Subjects and everyday life of schooling. In: GOODSON, I.; ANSTEAD, C.; MARSHALL MANGAN, J. Subject knowledge: readings for the study of school subjects. London: Falmer Press, 1998. p.45-59.

KOSIK, K. Dialética do concreto. Rio de Janeiro: Paz e Terra, 1986.

LEFÈBVRE, H. La Notion de totalité dans les sciences sociales. Cahiers Internationaux de Sociologie. Paris: PUF, v. I8, p.55-77, jan.juii. 1955.

LOPES, A. C. Conhecimento escolar. ciências e cotidiano. Rio de Janeiro: Eduerj, 1999.

LOPES, A. R. C. Políticas de currículo: continuidade ou mudança de rumos? Revista Brasileira de Educação, São Paulo, n.26, p. 109-1 18, 2004.

Políticas de currículo: mediação por grupos disciplinares de ensino de ciências e matemática. In: LOPES, A. R. C. MACEDO, E. F. de (orgs.) Currículo de ciências em debate. São Paulo: Papirus, 2004a. p. I-20.

LOPES, A. C.; MACEDO, E. O Pensamento curricular no Brasil. In: LOPES, A. C.; MACEDO, E. (orgs.) Currículo: debates contemporâneos. São Paulo: Cortez, 2002. p. I3-54.

LYOTARD, J. O Pós-moderno. Rio de Janeiro: José Olympio, 1986.

MACEDO, E. et al. Relatório da pesquisa "O Estado da arte do currículo da educação básica (1996-2002)". Brasília: Inep/PNUD, 2004.

McLAREN, P. Multiculturalismo crítico. São Paulo: Cortez, 1997. Multiculturalismo e a crítica pós-moderna: por uma pedagogia de resistência e transformação, p.54- 104. 
Relações macro/micro...

- Pedagogia crítica y cultura depredadora. Barcelona: Paidós, 1997a.

Posmodernismo, poscolonialismo y pedagogia, p.205-236:

McLAREN, P.; GIROUX, H. La Pedagogia radical como política cultural: más allá del discurso de la crítica y el antiutopismo. In: McLAREN, P. Pedagogía crítica y cultura depredadora. Barcelona: Paidós, 1997. p.47-78.

NÓVOA, A. (org). As Organizaçôes escolares em análise. Lisboa: D. Quixote, 1995.

Recebido em: agosto 2005

Aprovado para publicação em: junho 2006 